Corrosion Reviews, 2020, pp. 20190109. https://doi.org/10.1515/corrrev-2019-0109

\title{
Role of Carbon and Nitrogen in the improvement of corrosion resistance of new powder metallurgy Co-Cr-Mo Alloys
}

\author{
C. Garcia-Cabezon ${ }^{\mathrm{a}^{*}}$, C. Garcia-Hernandez ${ }^{\mathrm{b}}$, M .L. Rodriguez-Mendez , G. Herranz ${ }^{\mathrm{c}}$, \\ F.Martin-Pedrosa ${ }^{a}$
}

${ }^{a}$ Materials Engineering, E.I.I., Universidad de Valladolid, Paseo del Cauce 59, 47011 Valladolid, Spain bUVASENS, E.I.I., Universidad de Valladolid, Paseo del Cauce 59, 47011 Valladolid, Spain 'UCLM PIM Research Laboratory. INEI-ETSII. Universidad de Castilla-La Mancha (UCLM). ETSI Industriales, E-13071 Ciudad Real, SPAIN.

* Corresponding author. Tel.: +34 983423389;. e-mail address: crigar@eii.uva.es

\begin{abstract}
Microstructural changes that result in relevant improvements in mechanical properties and electrochemical behavior can be induced by the use of different sintering conditions of ASTM F75 Cobalt alloys during their processing through powder metallurgy technique.

It has been observed that the increase in carbon and nitrogen content improves corrosion resistance and mechanical properties as long as the precipitation of carbides and nitrides is avoided thanks to the use of rapid cooling in water after the sintering stage. In addition, the reduction of the particle size of the powder improves the hardness and resistance to corrosion in both acid media with chlorides and phosphate buffer medium that simulates the physiological conditions for its use as a biomaterial.

These results lead to increased knowledge of the role of the carbon and nitrogen content in the behavior displayed by the different alloys studied.
\end{abstract}

Keywords: Co-Cr-Mo alloys, powder metallurgy, alloy design, corrosion

\section{Introduction}

The most common materials used in metallic implants are stainless steel (which conforms to the ASTM F138), cobalt-chromium-molybdenum alloys (ASTM F75 and F 799) and titanium alloys, all of them have advantages and disadvantages (Cramer, 2003; Hermawan, 2011; Kunčická, 2017) Ni-free Co-Cr-Mo alloys are widely used in the production of medical devices due to their excellent properties of strength, wear resistance and biocompatibility, which make these materials very suitable in the human body environment. So they are widely used as orthopedic and dental implants such as hip, knee and dental prostheses (Diseg, 1999; Manama, 2017; Niinomi, 2012; Buford, 2004; Liao, 2012). These implant materials must fulfil all the requirements of biocompatibility: not only those inducing no measurable harm to the host (in terms of cytotoxicity, carcinogenicity, mutagenicity, pyrogenicity and allergenicity) but also inducing high mechanical properties, especially strength, ductility and high-cycle fatigue behaviour, high wear and corrosion resistance, in order to properly lasts over long periods of time. 
Cobalt alloys show several advantages. Their corrosion resistance in biological solution is better than that of stainless steel (SS), their wear resistance is superior to those of SS and $\mathrm{Ti}$ alloys, and the danger of allergic reaction is lower than for SS (Valero, 2008). CoCr-Mo are the most interesting types of cobalt alloys as, in general terms, they show the highest corrosion resistance of all the Co alloys. This good behavior is related to the spontaneous formation of a passive oxide film on the alloy surface (Hiromoto, 2005; Kurosu, 2006). The passive film on these alloys consisted of oxide species of $\mathrm{Co}, \mathrm{Cr}, \mathrm{Mo}$, with a thickness of a few nanometers (Luo, 2017). During the rapid formation of the passive film, Cr was preferentially oxidized and the oxidation of Co delayed, according to the oxidation and reduction potentials of these elements. Therefore, $\mathrm{Cr}$ and Mo are enriched and Co is depleted in the surface oxide film (Tsustumi, 2016).

However, Co-Cr-Mo alloys show several disadvantages, their plasticity and workability are lower than for SS and Ti alloys and, therefore, their processing is difficult. Most of the Co-Cr-Mo medical devices have been manufactured using the casting technique. However, this processing technique has limitations because a heterogeneous microstructure with a coarse grain size and dendritic segregation is obtained, while low tensile and fatigue strength are also found (Yamanaka, 2016; Yoda, 2012). Powder metallurgy (PM) is then seen as a good alternative for the design and manufacturing of medical devices.

The PM processing provides feasible and economic manufacturing of complex shaped devices, with such advantages as good dimensional precision and high surface finish. These porous Co-Cr-Mo components have good mechanical behavior, while the porosity improves bone fixation by reducing the difference between the elastic module of the implant and the surrounding bone. So PM technique has recently been used to obtain materials with controlled porosity and special properties. Dourandish et al. (Dourandish, 2008) have produced implants with a dense core and porous outer layer structure to promote tissue growth for better implant fixation. Oksiuta et al. (Oksiuta, 2009) and Adhullah et al. (Abdullah, 2016) also used PM to produce composite materials with bioactive glass as a reinforcement with better microstructural and mechanical behavior. Marek et al. (Marek, 2015) have proven that a PM Co-Cr-Mo alloy obtained by mechanical alloying and spark plasma sintering showed superior mechanical properties when compared to commercial cast cobalt alloys used for medical applications.

In PM processing, the effect of the sintering conditions has been studied by focusing on the microstructure, the physical and mechanical properties of the Co-Cr-Mo alloys. By controlling the sintering atmosphere, carbon and nitrogen are introduced in the Co-CrMo alloys. Carbon and nitrogen play an important role in the mechanical and corrosion properties of cast and wrought Co alloys.

The mechanical strength of Co-based alloys can be improved by solid solution, cold working, precipitation hardening, and grain refinement (Asgar, 1961). Precipitation strengthening in Co-based alloys results mostly from the formation of carbides or nitrides. Song et al. (Song, 2006) studied the carbide precipitation as a function of the sintering temperatures. Che Daud et al. (Che Daud \& Jamaludin, 2013) studied the effect of time/temperature on hardness and compressive strength. Oksiuta, et al.(Oksiuta, 2014) studied the effect of atmosphere/sintering temperature on ductility and mechanical 
properties. In the present work, the effect of sintering conditions such as atmosphere, time, temperature and cooling rate from sintering temperature are analyzed.

Moreover, PM components show a drawback related to corrosion resistance. Firstly, the resistance decreases as porosity increases due to a poor passive film stability and the increase in the area exposed to the corrosive media (Davis, J.R.1997). Few studies on the corrosion behavior of PM Co-alloys have been done to find solutions (Mohamed , 1999) and most of them use exclusively immersion tests (Che Daud, et al. 2013; Othman, 2010). However, in the present work, the corrosion behavior of PM Co-Cr-Mo will be undertaken by electrochemical techniques. In addition, corrosion resistance is improved by modifying the powder material (powder size) and sintering conditions (sintering atmosphere and cooling rate from sintering temperature).

Secondly, the precipitation of chromium carbides and nitrides could increase the corrosion susceptibility as a consequence of chromium depleted film while interstitials carbon and nitrogen can improve corrosion resistance. Yamanaka et al. (Yamanka, 2013, Yamanaka, 2014) found that the strength of hot rolled CoCr6Mo alloys monotonically increases when increasing nitrogen or carbon (Lee, 20026; Mori, 2015), but increasing the carbon also reduces the elongation-to-failure value and corrosion resistance. Valero Vidal et al. (Valero-Vidal, 2013) recommended lower percentages of carbon and homogenization heat treatments to form the oxide film and improve the corrosion resistance of as-cast Co-Cr-Mo alloys in a simulated body fluid. For melted Co-Cr with high chromium content, Tsustumit et al. (Tsustumi, 2016) concluded that interstitial nitrogen can increase corrosion resistance. Also, a new strategy is presented (Yamanaka, 2016), based on the simultaneous doping of nitrogen and carbon alloyed to obtain cast Cr-Co alloys with very high strength, comparable to that of wrought alloys, without loss of ductility and with comparable or superior corrosion resistance to conventional biomedical alloys. Therefore, it is necessary to perform corrosion resistance tests to understand the effects of carbon and nitrogen on PM alloys.

The conventional Co-Cr-Mo alloys are also good materials for use in a variety of aggressive environments (Tang, 2014), but the studies in other aqueous solutions have attracted significantly less attention than in biological media. Human et al. (Human, 1998) and Zhang et al. (Zhang, 2014) investigated the effect of alloying elements and microstructure on the corrosion behavior in sulfuric acid solution; they concluded that the addition of such alloy elements as $\mathrm{C}$ improved the corrosion resistance by stabilizing the FCC phase. Concerning the acid corrosion behavior of PM Co-Cr-Mo alloys, a recent study (Ding, 2018) revealed that carbide precipitates protect from corrosion in hydrochloric acid solution due to galvanic coupling. In this work, the corresponding performance evaluations of PM Co-Cr-Mo alloys with nitrogen and carbon in acidic chloride media and in phosphate buffer saline (PBS) at $37^{\circ} \mathrm{C}$ and $\mathrm{pH} 7.4$ are investigated. PBS is a suitable physiological environment to evaluate the corrosion in biological applications as it simulates the ionic strength of the human blood, its $\mathrm{pH}$ and its buffering capacity.

The aim of this work is to understand the microstructures, mechanical property (hardness) and corrosion behavior of PM Co-Cr-Mo alloys, combining three types of powder with the sintering conditions (time, temperature, atmosphere and cooling rate). The 
performances of the alloys in PBS simulated body fluids and in chloride acid solution are electrochemically evaluated by means of anodic potentiodynamic polarization curves. The correlation between microstructure, mechanical property and corrosion resistance are also discussed.

\section{Experimental}

\subsection{Materials}

Three Co-Cr-Mo water atomized powders were used as starting material, all identified as ASTM F75 CoCr Alloys (UNS R30075) (ASTM F75-18, 2018). They were characterized in terms of the carbon content and particle size. The low carbon powder had a carbon content of $0.005 \%$ and for the high carbon, the carbon content was $0.085 \%$. The powder particles have a rounded-shape, Fig. 1 , and $\mathrm{D}_{50}=6.3 \mu \mathrm{m}$ for the low particle size and $\mathrm{D}_{50}$ $=8.1 \mu \mathrm{m}$ for the high particle size. Table 1 shows the identification of the three powders, the chemical compositions, the $\mathrm{D}_{50}$ and the densities.

The carbon content was measured in a LECO CS-230 elemental analyzer, its absolute density by a Helio Accupyc II 1340 pycnometer, its particle size and distribution by a Micrometrics Sedigraph 5100 analyzer in the range of 300 to $0.1 \mu \mathrm{m}$, and its morphology by Scanning Electron Microscopy (SEM) in a JEOL microscope model JSM-6610LV.

Pre-sinterization heat treatment, at $950^{\circ} \mathrm{C}$ for one hour in a vacuum, was necessary due to the small size and rounded shape of the powders to improve the powder compaction (García-Cabezón, 2017). The pre-sinterized powders were uniaxially compacted using a floating die at $750 \mathrm{MPa}$ for $300 \mathrm{~s}$ using zinc stearate as lubricant. Two sintering atmosphere were used, some samples were sintered $\mathrm{N}_{2}-\mathrm{H}_{2}(95 \%-5 \%)$ and others were sintered in a vacuum, both at $1350{ }^{\circ} \mathrm{C}$ in for $60 \mathrm{~min}$. Also, two sinter-cooling conditions were performed for nitrogen sintered samples. One of these was referred as "furnacecooled" samples, i.e., FC using a slow rate of $5^{\circ} \mathrm{C} / \mathrm{min}$ (. The others were fast cooled in water, which were referred as "water-cooled" samples, i.e., WC. In the case of samples sintered in a vacuum, only slow cooling at a rate of $5{ }^{\circ} \mathrm{C} / \mathrm{min}$ was used because the fast cooling originated oxidation problems. The samples were designated as a number which indicates the alloy type, for example, $1 \mathrm{~N}$-WC means alloy 1 , a letter indicates the sintering atmosphere, for example $\mathrm{N}$ means sample sintered in nitrogen, and two additional letters indicate the cooling process after sintering, for example WC means water-cooled. Table 2 summarized the several types of samples prepared for testing. The contents in carbon, nitrogen and oxygen for every sample are shown in Table 3.

\subsection{Microstructural and mechanical characterization}

Densities of sintered compacts were calculated with pycnometer for solids. The fraction of porosity was determined by image analysis.

Samples were polished and etched before observation by optical metallography and scanning electron microscopy with energy dispersive analysis of X-rays (SEM/EDS). A SEM-FEI (QUANTA 200F) was used to record the images of the samples. Different etchings were tried but electrochemical etching with acid mixture $\left(\mathrm{HNO}_{3}-\mathrm{HCl}-\mathrm{H}_{2} \mathrm{O}\right)$ at $5 \mathrm{~V}$ during $45 \mathrm{~s}$ was selected. X-ray diffraction (XRD) using Agilent SuperNova, with AtlasS2 CCD, was implemented to help identify some phases. 
The Vickers hardness was evaluated by HV 30 using a Centaur 920 Durometer. In order to minimize the effect of porosity, microhardness test was also measured. The microhardness Vickers test was performed using a Matsuzawa MXT70 Microdurometer with $100 \mathrm{~g}$ for 30s. At least ten hardness tests were carried out with acceptable impressions; the microhardness was evaluated as the arithmetical mean value after the two lowest values were discarded.

\subsection{Electrochemical testing}

Potentiostat/galvanostat Model 273A EG\&G PAR was used for electrochemical tests. Potentiodynamic anodic polarization test were executed following ASTM G-5 (ASTM Standard G-5-87, 1993). Samples were finally polishing with $1 \mu \mathrm{m}$ diamond paste. During the test, nitrogen bubbling and agitation were used. Reference electrode was Saturated Calomel Electrode (SCE). Before the potentiodynamic scan a previous conditioning was used: 5 min delay at open circuit (OC) potential, $2 \mathrm{~min}$ at $-220 \mathrm{mV}_{\mathrm{SCE}}$, delay of $2 \mathrm{~min}$ at $\mathrm{V}_{\mathrm{OC}}, 1 \mathrm{~min}$ at $-600 \mathrm{mV}_{\mathrm{SCE}}, 5 \mathrm{~min}$ delay at $\mathrm{V}_{\mathrm{OC}}$. The anodic potentiodynamic scan started at $50 \mathrm{mV}_{\mathrm{SCE}}$ below $\mathrm{V}_{\mathrm{OC}}$, reaching $1000 \mathrm{mV}_{\mathrm{SCE}}$ at 50 $\mathrm{mV} / \mathrm{min}$ scan rate.

The tests were carried out in two electrolytes: an acid solution with chlorides containing $1 \mathrm{M} \mathrm{H}_{2} \mathrm{SO}_{4}+0.5 \mathrm{M} \mathrm{NaCl}$ with a temperature of $25^{\circ} \mathrm{C} \pm 1$ and $\mathrm{pH} \mathrm{3.0}$; and a PBS solution which chemical compositon was: $0.8 \mathrm{~g} / 1 \mathrm{NaCl}, 0.2 \mathrm{~g} / \mathrm{l} \mathrm{KCl}, 0.594$ g/l Na $2 \mathrm{HPO}_{4}, 0.2 \mathrm{~g} / \mathrm{l}$ $\mathrm{KH}_{2} \mathrm{PO}_{4}, \mathrm{pH} 7.44$, with a temperature of $37^{\circ} \mathrm{C} \pm 1$.

\section{Results and discussion}

\subsection{Microstructural characterization}

Figure 2 show the porosity and density of the samples. It can be seen that the particle size powder was the factor with the greatest influence on porosity. The density increased and the porosity decreased for samples sintered from alloy 1 , which had the smallest particle size. The size of the powder particles heavily influenced the compaction and sintering results. In addition, the sintering atmosphere also affected porosity. It is well known that interstitial nitrogen promotes an increase in atomic packing, as a consequence of retarding densification process. This originated a decrease in the atomic diffusion coefficients, so samples sintered in nitrogen showed a higher porosity than samples sintered in a vacuum. It was especially clear for WC samples. The highest porosity and the lowest density were found for N-WC samples, which were those with the highest interstitial nitrogen content, see Table 3. Carbon content affected porosity only slightly.

The microstructures were strongly conditioned by the kind of sintering atmosphere and the cooling rate. The optical microstructures of the samples sintered in nitrogen were complex and different from those of samples sintered in a vacuum, which were simpler, Fig. 3. Figure $3 \mathrm{a}$ presents the general structure observed for the sample sintered in a vacuum, 1V-FC, where grains showed precipitation in the boundary grain. For samples sintered in nitrogen, $1 \mathrm{~N}-\mathrm{FC}$, the Figures $3 \mathrm{~b}$ and $3 \mathrm{c}$ show a lamellar microstructure comprising cellular colonies, practically dissolved by the etchant attack. For the N-WC sample, no precipitates were observed. Figure $3 \mathrm{~d}$ reveals the microstructure of $1 \mathrm{~N}-\mathrm{WC}$, which was a fine grain matrix with twins and residual pores. The microstructural analysis of alloy 2 (with a larger particle size) was similar to alloy 1 . However, for the alloy $2 \mathrm{C}$ 
(with a high carbon content), after the FC, a more intense precipitation was mainly distributed in the boundary grain for 2CV-FC (Fig. 3e) and in the form of a lamellar constituent for 2CN-FC (Fig. 3f). This could be explained if it is considered that an intense carbide/nitride formation occurs when the carbon saturation level is reached.

The identification of the phases was carried out using an XRD analysis. Figure 4 shows that there were differences with respect to the sintering atmosphere and the cooling rate for alloy 2.The XRD analysis of alloy 1 (with a smaller particle size) was similar to alloy 2. For samples sintered in nitrogen, $\gamma$-FCC was the main phase, but not the only one, while for samples sintered in a vacuum, a mixture of $\gamma$-FCC and $\varepsilon$-HCP was observed, see Fig. 4a. As is well known, pure Co has a $\gamma$-FCC structure at high temperature and undergoes a transformation to an $\varepsilon-\mathrm{HCP}$ structure, which is stable at room temperature. The addition of the FCC-phase stabilizers, such as nitrogen or carbon, promotes the $\gamma$ FCC phase at room temperature (Park, 2018). Yamanaka et al. (Yamanaka, 2014) investigated the microstructure of Co-Cr-Mo alloys containing different concentrations of nitrogen (0-0.24 wt \%). They conclude that the volume fraction of the athermal $\varepsilon$ (hcp) martensite phase decreased with increasing nitrogen concentration, and a fully $\gamma$ (fcc) matrix structure was obtained in the specimens with nitrogen concentrations greater than $0.10 \mathrm{wt} \%$ [26]. In this work, all alloys sintered in nitrogen were primarily $\gamma$-FCC because the addition of nitrogen suppressed the athermal $\gamma$-FCC $\rightarrow \varepsilon$-HCP martensitic transformation since nitrogen sintered samples had a concentration of over $0.10 \%$. Some low intensity additional peaks can be seen, which indicates secondary phase precipitation. For samples sintered in a vacuum, Fig. $4 \mathrm{a}$, the $\sigma$-phase and $\mathrm{M}_{23} \mathrm{C}_{6}, \mathrm{M}_{7} \mathrm{C}_{3}$ carbides can be identified, while for samples sintered in a nitrogen atmosphere, Fig. 4b, carbides and nitrides $\mathrm{M}_{2} \mathrm{X}$ could be detected, especially for samples from alloy $2 \mathrm{C}$ with a higher carbon content, Fig. 4c. Increasing the nitrogen and carbon concentrations retards the formation of the $\sigma$-phase and, consequently, stabilizes the nitride/carbide phases, which is generally observed in cast biomedical Co-Cr-Mo-C alloys (Lee, 2006; Mori, 2015; Caudillo, 2002). The water cooling promoted the lowest amount of carbide/nitride precipitates, see Fig. 4d.

SEM/EDS was used to identify some phases. Figure 5a shows a SEM image for 2CNWC. The twined $\gamma$-FCC grain and pore areas are shown and, additionally, some light globular particles were identified as silica oxide by EDS, they arise from the oxidation of the silicon of the powder. Figure 5b shows the lamellar constituent formed in 2CN-FC. EDS analysis confirmed that the lamella had a higher concentration of chromium/carbon and nitrogen than the matrix. The matrix showed chromium depletion and a higher cobalt content. This lamellar constituent was also reported in cast Co-Cr-Mo alloys (Park, 2018; Rosenthal 1986) and another alloy systems, such as stainless steels (Mori, 2014). The morphology of the lamellar colonies suggests a possible growth by discontinuous (cellular) precipitation, whereby the coupled lamellae growth is controlled by boundary grain diffusion. Based on TEM studies, Kilner et al. (Kilner, 1982) reported that the lamellar constituent consisted of alternate lamellae of carbide type $\mathrm{M}_{23} \mathrm{C}_{6}$ and a $\gamma$-FCC cobalt rich matrix. Their result is consistent with the chemical composition measured by EDS, as shown in Table 4 and Figure 5c; although, in our case, the lamellar constituent could be a nitride/carbonitride type $\mathrm{M}_{2} \mathrm{X}$ due to the high nitrogen content of the alloy. The authors have previously reported the formation of this lamellar constituent during furnace cooling of stainless steels (García, 2010). Figure 5d shows a SEM micrograph 
with intergranular precipitates for $2 \mathrm{CV}-\mathrm{FC}$. They could be identified as carbides, type $\mathrm{M}_{23} \mathrm{C}_{6}$ or $\mathrm{M}_{7} \mathrm{C}_{3}$. On the contrary, most of these precipitates for low-carbon alloys were only enriched in chromium, so they could be considered to be the $\sigma$-phase and in agreement with the results observed in cast Co-Cr-Mo alloys (Mori, 2015; Park, 2018).

\subsection{Macro- and microhardness}

The results of the Vickers macro- and microhardness tests confirmed that the sintering atmosphere was a relevant factor, Fig. 6. All alloys sintered in an $\mathrm{N}_{2}-\mathrm{H}_{2}$ atmosphere had higher macro/microhardness than those sintered in a vacuum. Adding nitrogen is a promising method for improving the mechanical properties of biomedical cast and forged $\mathrm{Co}-\mathrm{Cr}-\mathrm{Mo}$ alloys. The strength increases with increasing nitrogen concentrations as $\mathrm{M}_{2} \mathrm{X}$ precipitates increase and they stabilize the $\gamma$-FCC matrix, which improves ductility (Yamanaka, 2013; Yamanaka, 2014; Mori, 2014; Mori et al. 2014). As expected, such hardening effects also happened for PM samples. The nitrogen addition increased the hardness, especially for FC samples, due to the presence of the cellular constituent with $\mathrm{M}_{2} \mathrm{X}$ lamellar precipitates. On the other hand, the precipitate-free WC samples exhibited a higher hardness than the V-FC samples; in this case, the interstitial nitrogen in the $\gamma$ FCC phase acted as an effective element in strengthening both the solid solution and the grain size.

A second factor to analyze was the effect of the type of powder. Alloy 1, with a lower particle size, was harder than alloy 2 . The highest density and lowest porosity, observed in alloy 1, could explain this increase in hardness. It is known that a low level of porosity can be assumed to be the main factor for the high hardness value (Dourandish, 2008). It is especially clear for macrohardness, see Fig. 6a, because this test is more susceptible to the porosity effect. Focusing on the carbon content, it was found that increasing the amount of carbon in the powder (alloy 2C) improved the hardness, especially for FC samples, because the added carbon promotes an increase in carbide precipitates. Carbide precipitation is primarily important in strengthening conventional Co-Cr-Mo alloys (Yamanaka, 2016; Song, 2006; Yamanaka, 2014; Narushima, 2013). It is worth noting that the presence of fine carbide precipitates in the intragranular regions increases the strength of an alloy (Liao, 2012) more than coarse particles, so the hardening effect was more visible for sample sintering in a vacuum. The hardening by grain size refinement was clear for sample N-WC. Finally, samples sintered in nitrogen and cooled in water have a finer grain size than those sintered in a vacuum (Table 3), which also justifies their higher hardness. Therefore, the hardness of the samples increases with the presence of nitrogen, both in solid solution and in the form of precipitates. It also increases with the lowering in porosity and with the refinning of the grain size.

\subsection{Electrochemical behavior}

Potentiodynamic polarization methods were used for corrosion testing. This technique provides useful information regarding the corrosion mechanisms and susceptibility of materials to corrosion in different environments. In this case, a typical acid solution was used to understand the generic corrosion behavior of PM samples, as well as a specific 
and very common simulated body fluid such as PBS. The latter gives some insights about the behavior of PM materials in contact with the human body. The factors to study in this work were the processing of such parameters as the type of alloy, sintering atmosphere or cooling procedure. The oxygen content was similar in all samples so that the effect from the point of view of corrosion was negligible. The shape of the potentiodynamic polarization curves reflected the influence of every factor.

Figure 7 shows the potentiodynamic curves of some N-FC samples in the two solutions, the acid $\mathrm{NaCl}$ and the neutral PBS. The typical characteristics can be observed on these curves: cathodic domain, cathodic-anodic transition, passive domain and transpassive domain.

The first domain, where the current density was negative due the reduction of water, was very similar for the two solutions. Following that, the largest dissimilar values were registered in the range where the material was dissolved and passivated. In acid $\mathrm{NaCl}$, an anodic dissolution zone was observed, from which a passive layer was formed, exhibiting a broad range. In PBS, a narrower passive range was observed, in which the current density increased when the potential increased, until a breakdown potential at about 0.6 $\mathrm{V}_{\mathrm{SCE}}$ was reached.

The passive current density ( $\mathrm{i}_{\text {pass }}$ ) was lower in PBS than in acid $\mathrm{NaCl}$; however, the passive range was smaller (from 0.20 to $0.60 \mathrm{~V}_{\mathrm{SCE}}$ ) in PBS than in acid $\mathrm{NaCl}\left(-0.2 \mathrm{~V}_{\mathrm{SCE}}\right.$ to $0.97 \mathrm{~V}_{\mathrm{SCE}}$ ). This could be explained by considering that the phosphate ions slightly increased the $i_{\text {pass}}$, shifted the breakdown $\left(\mathrm{E}_{\mathrm{b}}\right)$ potential towards more cathodic potentials and showed a shoulder at approximately 0.6 to $0.7 \mathrm{~V}_{\text {SCE }}$. This phenomenon was also observed by Milosev et. al (Milosev, 2003) and Valero Vidal et. al (Valero Vidal, 2011) and was attributed to the formation of phosphate-chromium ion complexes that activated the transpassive dissolution.

The results showed that the acid solution was more corrosive than the PBS, although the passive film formed in this latter showed a lower $\mathrm{E}_{\mathrm{b}}$. It is well established that lowering the $\mathrm{pH}$ enhances the localized corrosion (Okazaki, 2008). Usually, the shapes of the potentiodynamic curves obtained in neutral and acidic solutions showed no apparent difference, but the $\mathrm{E}_{\mathrm{b}}$ decreased, and $\mathrm{i}_{\text {pass }}$ increased as the $\mathrm{pH}$ value decreased; indicating that the corrosion resistance decreased with low $\mathrm{pH}$. This appears to agree with the observed $i_{\text {pass }}$, which decreased with an increase in $\mathrm{pH}$ from 3 to 7.4. Furthermore, the decrease in $\mathrm{i}_{\text {pass }}$ could be attributed to the changes in the composition and thickness of the passive film. In this work, the $\mathrm{E}_{\mathrm{b}}$ was smaller for PBS solution with higher $\mathrm{pH}$, then it is concluded that it is associated to the phosphate ions formation in passive film. The same behavior was observed for all types of powder and all sintering conditions. The influence of every processing parameter is analyzed in the next two sections.

\subsubsection{Electrochemical behavior in acid $\mathrm{NaCl}$ solution}

It can be seen that the most influencing parameters are the sintering atmosphere and the cooling rate. Figure $8 \mathrm{a}$ shows the anodic polarization curves of alloy 2 . The lowest corrosion potential $\left(\mathrm{E}_{\mathrm{corr}}\right)$ corresponded to $2 \mathrm{~N}-\mathrm{WC}$, but there was also a remarkable beneficial effect on the stability of the passive film. For $2 \mathrm{~V}-\mathrm{FC}$, the anodic curve 
morphology was similar to $2 \mathrm{~N}-\mathrm{FC}$, but with slightly higher current densities. Active and passive current densities clearly decreased when the cooling rate increased for the samples sintered in nitrogen. These effects were also visible in anodic scans of alloys 1 and $2 \mathrm{C}$.

The observed behavior can be explained by considering the influence of the sintering conditions on the microstructure. It is known that conventional Co alloys with an FCCstructure display improved corrosion behavior compared to those with an HCP-structure in acid solution. This has been investigated in pure $\mathrm{Co}$ and in Co alloys. For pure Co, the addition of FCC-stabilizing elements improves the corrosion resistance in the $\mathrm{H}_{2} \mathrm{SO}_{4}$ solution up to four times more than that of pure Co (hcp) (Human, 1998). For Co alloys, Zhang et al. (Zhang, 2014) studied the corrosion behavior of FCC and HCP conventional Co-Cr-Mo alloys; they observed that the polarization curves of the two phases overlapped each other from the passive to the transpassive region.

It can also be observed that the $\mathrm{E}_{\text {corr }}$ shifted to the cathodic potential when the cooling rate increased, Fig. 8a. In general, grain refining leads to an increase in anodic reaction and causes a negative shift of $\mathrm{E}_{\text {corr }}$ (Hiromoto, 2005). Therefore, the smaller grain size in the FCC phase might be a contributing factor to the relatively low value of $\mathrm{E}_{\text {corr }}$. Furthermore, the microstructure of the $2 \mathrm{~N}-\mathrm{WC}$ sample was much more homogeneous, so a better corrosion behavior was expected. The lamellar constituent observed for the $2 \mathrm{~N}$ FC sample can act as preferential sites for corrosion attack, due to the formation of galvanic microcells between the $\mathrm{Cr}$-rich precipitates and the $\mathrm{Cr}$-depleted areas surrounding the FCC-matrix. Consequently, the $\mathrm{xN}-\mathrm{WC}$ samples showed the lowest $\mathrm{i}_{\text {pass. }}$.

No pitting was observed and high transpassive potentials were measured in all the alloys for any of the sintering conditions tested. This result is expected if it is considered that most of the research resulted in the fact that the chromium content is the key factor in the passive current differences between the alloys( Kurosu, 2006; Human, 1998; Sun, 2013).

To complete the analysis of the electrochemical behavior in acid $\mathrm{NaCl}$, it is worth analyzing the influence of the type of alloy. The most important differences were observed for N-FC, Fig. 8b. The lowest passive current density appeared in alloy 1 due to its lowest porosity, while the highest current density corresponded to alloy $2 \mathrm{C}$, which is richer in $\mathrm{C}$. This agrees with other studies about the advantages and disadvantages of carbon addition. The said studies have shown that carbon addition is a simple way of enhancing the strength and hardness of biomedical cast $\mathrm{Co}-\mathrm{Cr}-\mathrm{Mo}$ alloys, but reduces their ductility and corrosion resistance. Bettini et al. (Bettini, 2013) reported that the formation of the chromium carbide phase is detrimental to corrosion, depleting the metal matrix in $\mathrm{Cr}$, which is known to be responsible for the passivity of Co-Cr-Mo alloys. Thus, a lower amount of $\mathrm{Cr}$ available to form the oxide film (because of carbide/nitride formation due to the low cooling rate and/or the higher carbon content in the bulk alloy) generates a more heterogeneous surface and decreases the alloy's corrosion resistance.

\subsubsection{Electrochemical behavior in neutral PBS solution}

The analysis performed in the previous section is replicated here, but with PBS as the electrolyte, since this simulates the typical biological conditions. The analysis was done 
under a comparative basis to elucidate the nature of the corrosion behavior of these PM Co alloys in PBS.

Figure 9a shows the potentiodynamic curves of alloy 1 in the PBS solutions for the three sintering conditions. They were similar to those observed in acid $\mathrm{NaCl}$. As expected, because of its microstructure, the best behavior corresponded to $1 \mathrm{~N}-\mathrm{WC}$, which showed the lowest current density, the highest $\mathrm{E}_{\mathrm{b}}$ and the lowest $\mathrm{E}_{\text {corr. }}$ The differences for every sintering condition were less evident than those registered in acid $\mathrm{NaCl}$.

The electrochemical parameters are collected in Table 5. The values of $i_{\text {pass }}$ were extracted from the polarization curves at the applied potential of $0.25 \mathrm{~V}_{\mathrm{SCE}}$ (potential lying within the passive region). The $\mathrm{E}_{\text {corr }}$ shifted towards more positive values when PBS was the electrolyte. It was especially clear that, for samples sintered in a vacuum, a nobler corrosion potential was observed in the PBS solutions.

For every sample, the cathodic and passive current densities were lower in PBS than in acid solution. Similar results were found by Valero Vidal et al. [10] when analyzing the electrochemical behavior of conventional Co-Cr-Mo alloys in PBS solutions. It can be concluded that phosphates act as an anodic inhibitor (the slope of anodic branch diminishes with respect to the anodic branch in the $\mathrm{NaCl}$ solution). $\mathrm{HPO}_{4}{ }^{-2}$ and $\mathrm{H}_{2} \mathrm{PO}_{4}{ }^{-2}$ could be adsorbed in the Co alloy and would form a film on it, which then decrease the interaction between the passive film and the corrosive solution, delaying the corrosion initiation. The main differences between the two test solutions were observed in the transpassive domain. For all sintering conditions in PBS, a current density peak was observed at 0.6-0.75 $\mathrm{V}_{\mathrm{SCE}}$ due to the formation of phosphate-chromium ion complexes in addition to the transpassive dissolution of the chromium oxide, as well as the water oxidation observed in the $\mathrm{NaCl}$ solution.

The $\mathrm{E}_{\mathrm{b}}$ values registered in PBS were similar to those observed for conventional Cr-CoMo alloys (Valero Vidal, 2011), or even more positive in the case of nitrogen sintered samples, due to the beneficial effect of interstitial nitrogen in the FCC solid solution. On the contrary, carbon promoted a deleterious effect for samples sintered in nitrogen and furnace cooled, as can be observed in Figure $9 \mathrm{~b}$ and table 5, while a higher carbon content in the powder shifted the corrosion potential towards lower values, increased the $i_{\text {pass }}$ values and lowered the $E_{b}$ values due to the chromium carbide precipitation and their chromium depletion effect on the passive film. Regarding the particle powder size, the best corrosion behavior was found for samples obtained from lower particle sizes due the higher density, showing more noble potentials and lower current densities.

\section{Conclusions}

Powder metallurgy led to the production of Cr-Co-Mo alloys rich in carbon and nitrogen, which is very difficult to obtain by other processing techniques.

The sintered alloys from smaller sized powders are those showing a higher density, lower porosity, higher hardness and better electrochemical performance in both acid medium with chlorides and in PBS. 
The interstitial nitrogen introduced in the sintering stage inhibits the transformation from the $\gamma$-phase to the $\varepsilon$-phase; causing an increase in hardness and corrosion resistance. This beneficial effect is especially important in water-cooled samples. The rapid cooling inhibits the formation of the lamellar constituent, which decreases corrosion resistance.

Increasing the carbon content gives rise to a greater amount of chromium rich precipitates, especially in the furnace-cooled samples. These precipitates increase the hardness, but decrease corrosion resistance.

The effect of sintering conditions on the anodic polarization behavior is similar in acid $\mathrm{NaCl}$ and PBS solutions, although the former has been shown to discriminate more easily between the two sinter-cooling rates. Comparing anodic polarization measurements in both solutions, acid $\mathrm{NaCl}$ curves show higher corrosion and passive current densities, but with a more stable and wider passive range than PBS curves. The breakdown potential is higher in the acid $\mathrm{NaCl}$ solution.

The electrochemical behavior in the acid $\mathrm{NaCl}$ and $\mathrm{PBS}$ solutions of these novel porous materials reveals that it is similar, or even better, for conventional ASTM $75 \mathrm{Co}-\mathrm{Cr}-\mathrm{Mo}$ alloys. The PM alloys sintered in nitrogen and water-cooled show the best performance due to an improved homogeneous and fine-grain $\gamma$-structure with interstitial nitrogen in solid solution.

\section{Acknowledgments}

Financial support by MINECO-FEDER (AGL2015-67482-R), Junta de Castilla y Leon and FEDER (VA275P18) is gratefully acknowledged, and Junta de Castilla y León (VA044G19) (BOCYL-D-09072019-11).

\section{References}

Abdullah R., Adzali N.M.S, Daud Z.C., Bioactivity of a Bio-composite Fabricated from CoCrMo/Bioactive Glass by Powder Metallurgy Method for Biomedical Application, 5th international conference on recent advances in materials, minerals and environment $(\&$ 2nd international postgraduate conference on materials, mineral and polymer, Procedia Chemistry, 19 (2016) 566-570.

Asgar K., Peyton F.A., Effect of microstructure on physical properties of cobalt-based alloys, J. Dent. Res. 40 (1961) 63-72.

ASTM F75-18, Standard Specification for Cobalt-28 Chromium-6 Molybdenum Alloy Castings and Casting Alloy for Surgical Implants (UNS R30075), ASTM International, West Conshohocken, PA, 2018.

ASTM Standard G-5-87, Standard reference test method for making potentiostatic and potentiodynamic anodic polarization measurements, ASTM, Philadelphia, 1993.

Bettini E., Leygraf C., Pan J., Nature of current increase for a CoCrMo alloy: Transpassive dissolution vs. water oxidation, Int. J. Electrochem. Sci. 8 (2013)1179111804. 
Buford A., Goswami T., Review of wear mechanisms in hip implants: paper I. General. Mater. Des. 25 (2004) 385-393.

Caudillo M., Herrera-Trejo M., Castro M.R., Ramírez E., González C.R., Juárez J.I., On carbide dissolution in an as-cast ASTM F-75 alloy, J. Biomed. Mater. Res. 59 (2002), 378-385.

Che Daud Z., Jamaludin S. B., Derman M.N., Wahab J.A., The corrosion studies of powder metallurgy Co-Cr-Mo (F-75), Adv. Environmental Biology, 7(12) 2013 37163719 .

Che Daud Z., Jamaludin S.B., The effect of sintering on the properties of powder metallurgy (PM) F-75 Alloy. Adv. Mater. Res. 795 (2013) 573-577.

Cramer S.D., B.S. Covino, ASM Handbook. Vol 13A. Corrosion: Fundamentals, Testing and Protection. Materials Park, OH USA, ASTM International (2003).

Davis, J.R., Metallurgy, processing, and properties of superalloys, Heat- Resistant Materials, ASM Specialty Handbook. ASM International, Ohio (1997) 235-254.

Ding J., Zhang Y., Corrosion Behavior of Powder Metallurgical Cobalt-Based Alloys in Hydrochloric Acid, Corrosion Conference Paper, (2018) 475.

Disegi J.A., Kennedy R.L., Pilliar R., Cobalt-Base Alloys for Biomedical Applications, STP1365 (1999).

Dourandish M. , Simchi D.G.A., Firouzdor V., Sintering of biocompatible P/M Co-CrMo alloy (F-75) for fabrication of porosity-graded composite structures Mater. Sci. Eng. A 472 (2008) 338-46.

García C., Martín F., Blanco Y., Aparicio M.L., Effect of ageing heat treatments on the microstructure and intergranular corrosion of powder metallurgy duplex stainless steel, Corrosion Science 52 (2010) 3725-3737.

Garcia C., Martin F., Blanco Y., De Tiedra M.P., Aparicio M.L., Influence of Sintering under Nitrogen Atmosphere on Microstructures of Powder Metallurgy Duplex Stainless Steels, Metallurgical and Materials Transactions A, 40A, 2009, 292-301.

Garcia-Cabezon C., Blanco Y., Rodriguez-Mendez M.L., Martin-Pedrosa F., Characterization of porous nickel-free austenitic stainless steel prepared by mechanical alloying, Journal of Alloys and Compounds 716 (2017) 46-55.

Hermawan H., Ramdan D., Djuansjah J.R.P., Biomedial Enineering, Metal for Biomedical Applications, Rijeka, Croatia, In Tech Ed (2011).

Hiromoto S., Onodera E., Chiba A., Asami K., Hanawa T., Microstructure and corrosion behavior in biological environments of the new forged low-Ni Co-Cr-Mo alloys, Biomaterials 26 (2005) 4912-4923.

Human A., Roebuck B., Exner H., Electrochemical polarization and corrosion behavior of cobalt and Co (W, C) alloys in 1 N sulphuric acid, Mater. Sci. Eng. A241 (1998) 202210. 
Kilner T., Pilliar R. M., Weatherly G. C., Allibert C., Phase identification and incipient melting in a cast Co-Cr surgical implant alloy. J. Biomed. Mater. Res. 16 (1982) 63-69.

Kunčická L., Lowe T.C., Kocich R., Advances in Metals and Alloys for Joint Replacemente, Progress in Materials Science,88 (2017) 232-280.

Kurosu S., Nomura N., Chiba A., Effect of sigma phase in Co-29Cr-6Mo alloy on corrosion behavior in saline solution, Mater. Trans. 47, 8 (2006) 1961-1964.

Lee S.H., Takahashi E., Nomura N., Chiba A., Effect of carbon addition on microstructure and mechanical properties of a wrought $\mathrm{Co}-\mathrm{Cr}-\mathrm{Mo}$ implant alloy, Mater. Trans. 47 (2006) 287-290.

Liao Y., Pourzal R., Stemmer P., Wimmer M.A., Jacobs J.J., Fischer A., Marks L.D., New insights into hard phases of CoCrMo metal-on-metal hip replacements, J. Mech. Behav. Biomed. Mater. 12 (2012) 39-49.

Liao Y., Pourzal R., Stemmer P., Wimmer M.A., Jacobs J.J., Fischer A., Marks L.D., New insights into hard phases of CoCrMo metal-on-metal hip replacements, J. Mech. Behav. Biomed. Mater. 12 (2012) 39-49.

Luo H., Dong C.F., Xiao K., Li X.G., Passive Film Properties and Electrochemical Behavior of Co-Cr-Mo Stainless Steel in Chloride Solution, J. Mater. Eng. Perform. 26, 5 (2017) 2237-2243.

Manama N.S., Harunb W.S.W., Shrib D.N.A., Ghanib, Kurniawanc T., Ismaild, M.H. Ibrahim M.H.I., Study of corrosion in biocompatible metals for implants: A review, J. Alloys and Compounds 701 (2017) 698-715.

Marek P., Nováka J., Mlynára D., Vojt¥cha T.F., Kubatík B., Málekca J., Powder metallurgy preparation of Co-based alloy for biomedical applications, Act. Phys. Polonica A.128 (2015), 334-343.

Milosev I., Strehblow H.-H., The composition of the surface passive film formed on CoCrMo alloy in simulated physiological solution, Electrochim. Act. 48 (2003) 27672774.

Mohamed K.E., Gad M.M.A., Nassef A.E., El-Sayed A.W.A., Localized corrosion behaviour of powder metallurgy processed cobalt-base alloy stellite- 6 in chloride environments, Zeitschrift für Metallkunde, 90 (1999) 195-202.

Mori M., Yamanaka K., Chiba A., Effect of cold rolling on phase decomposition in biomedical $\mathrm{Co}-29 \mathrm{Cr}-6 \mathrm{Mo}-0.2 \mathrm{~N}$ alloy during isothermal heat treatment at $1073 \mathrm{~K}, \mathrm{~J}$. Alloys Comp. 612 (2014) 273-279.

Mori M., Yamanaka K., Kuramoto K., Ohmura K., Ashino K., Chiba A., Effect of carbon on the microstructure, mechanical properties and metal ion release of $\mathrm{Ni}$-free $\mathrm{Co}-\mathrm{Cr}-\mathrm{Mo}$ alloys containing nitrogen, Mater. Sci. Eng. C, 55, (2015) 145-154.

Narushima N., Mineta S., Kurihara Y., Ueda K., Precipitates in biomedical Co-Cr alloys, JOM 65 (2013) 489-502. 
Niinomi M., Nakai M., Hieda J., Development of new metallic alloys for biomedical applications, Acta Biomater. 8 (2012) 3888-3903.

Okazaki Y, Gotoh E., Metal release from stainless steel, $\mathrm{Co}-\mathrm{Cr}-\mathrm{Mo}-\mathrm{Ni}-\mathrm{Fe}$ and $\mathrm{Ni}-\mathrm{Ti}$ alloys in vascular implants, Corrosion Science 50 (2008) 3429-3438.

Oksiuta Z., Dabrowski J. R., Olszyna A., Co-Cr-Mo-based composite reinforced with bioactive glass, J. Materials Processing Technology, 209 (2009) 978-985.

Oksiuta Z., Dabrowski J.R., Ratuszek W., Structure of porous samples of Co-Cr-Mo alloy, Arch. Metall. Mater. 49 (2004) 949-960.

Othman R., Jamaludin S.B., Derman M.N. , The corrosion study of Co-Cr-Ni alloy fabricated by powder metallurgy Proceedings of ICXRI 2010International Conference on X-Rays \& Related Techniques in Research \& Industry June 9- 10, (2010) Aseania Resort

Langkawi.Yamanaka K., Mori M., Chiba A., Nanoarchitectured Co-Cr-Mo orthopedic implant alloys: nitrogen-enhanced nanostructural evolution and its effect phase stability, Acta Biomater. 9 (2013) 6259-6267.

Park J.B., Jung K.H., Kim K.M., Son Y., Lee J.I., Ryu J.H., Microstructure of As-cast Co-Cr-Mo Alloy Prepared by Investment Casting, J. Korean Phys.Soc.72 (2018) 947951.

Rosenthal R., West D. R. F., Discontinuous $\gamma^{\prime}$-precipitation in directionally solidified IN 738 LC alloy. Mater. Sci. Technol. 2 (1986) 169-174.

Song C. B., Park H. B., Seong H. G., López H. F., Development of athermal and isothermal $\varepsilon$-martensite in atomized $\mathrm{Co}-\mathrm{Cr}-\mathrm{Mo}-\mathrm{C}$ implant alloy powders, Acta Biomater. 2 (2006) 685-691.

Sun M., iaoK. X, Dong C.F., Li X.G.,Zhong P., Effect of pH on semiconducting property of passive film formed on ultra-high-strength corrosion-resistant steel in sulfuric acid solution, Metall. Mater. Trans. A, 44 (2013) 4709-4717.

Tang N., Li, Y. Koizumi Y., Chiba A., Effect of nitriding treatment on corrosion behaviour of Co-Cr-Mo alloy in liquid Al, Corros. Sci. 78 (2014) 244-251.

Tsustumi Y., Doi H., Nomura N., Ashida M., Chen P., A.K. Awasaki, T. Hanawa, Surface Composition and Corrosion Resistance of Co-Cr Alloys Containing High Chromium, Mater. Trans. 57, 12 (2016) 2033-2040.

Valero Vidal C., Igual Muñoz A., Electrochemical characterisation of biomedical alloys for surgical implants in simulated body fluids Corrosion Science 50 (2008) 1954-1961.

Valero Vidal C., Igual Muñoz A., Effect of physico-chemical properties of simulated body fluids on the electrochemical behaviour of CoCrMo alloy, Electrochimica Acta 56 (2011) 8239-8248.

Valero-Vidal C., Casabán-Julián L., Herraiz-Cardona I., Igual-Muñoz A. Influence of carbides and microstructure of CoCrMo alloys on their metallic dissolution resistance Mater. Sci. Eng. C 33 (2013) 4667-4676. 
Yamanaka K., Mori M., Chiba A., Effects of nitrogen addition on microstructure and mechanical behavior of Co-Cr-Mo alloys for orthopedic applications, J. Mech. Behav. Biomed. Mater. 29 (2014) 417-426.

Yamanaka KMori., M., Chiba A., Developing high strength and ductility in biomedical Co-Cr cast alloys by simultaneous doping with nitrogen and carbon, Acta Biomaterialia 31 (2016) 435-447.

Yoda K., Suyalatu K., Takaichi A., Nomura N., Tsutsumi Y., Doi H., Kurosu S., Chiba A., Igarashi Y., Hanawa T., Effects of chromium and nitrogen content on the microstructuresand mechanical properties of as-cast $\mathrm{Co}-\mathrm{Cr}-\mathrm{Mo}$ alloys for dental applications, Acta Biomater. 8 (2012) 2856-2862.

Zhang X.Q., Li Y.P., Tang N., Onodera E., Chiba A., Corrosion behaviour of CoCrMo alloys in $2 \mathrm{wt} \%$ sulphuric acid solution, Electrochim. Act, 125,(2014) 543-555. 